\title{
Correction to: Constraining the carbonate system in soils via testing the internal consistency of $\mathrm{pH}, \mathrm{pCO}_{2}$ and alkalinity measurements
}

Sima Bargrizan ${ }^{1 *}$, Ronald J. Smernik ${ }^{1}$ and Luke M. Mosley ${ }^{2}$

\section{Correction to: Geochem Trans (2020) 21:4}

\section{https://doi.org/10.1186/s12932-020-00069-5}

The original version of this article unfortunately contained a mistake. The presentation of Fig. 4 was incorrect. That is, in Fig. 4, the bottom graph in the figure should be removed.

The correct version of Fig. 4 is given below.

The original article has been corrected [1]. 


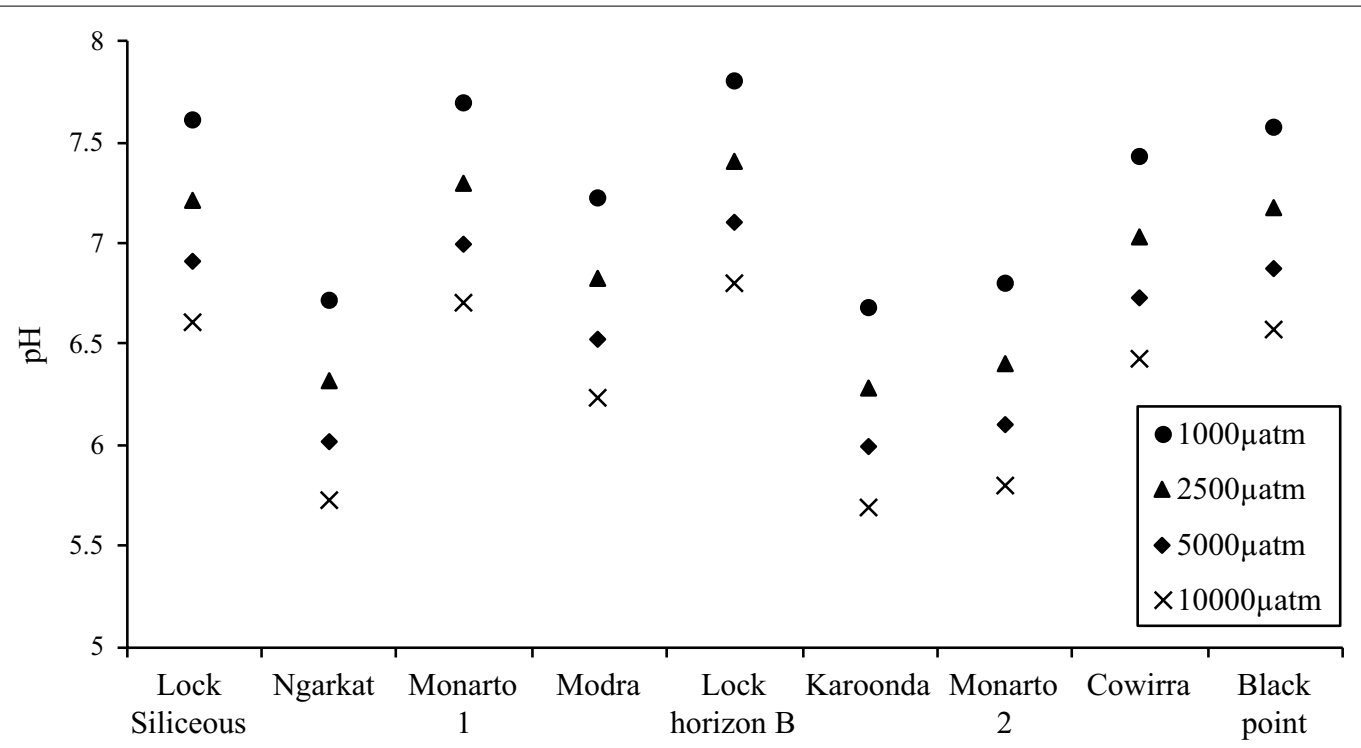

Fig. 4 The mean pH calculated for the different $\mathrm{pCO}_{2}\left(400,1000,2500,5000,10,000 \mu\right.$ atm $\left.\mathrm{pCO}_{2}\right)$ concentrations using the carbonate system model for the 9 soil samples

Author details

${ }^{1}$ The School of Agriculture, Food and Wine, The University of Adelaide, Waite Campus, Adelaide, SA 5064, Australia. ${ }^{2}$ Acid Sulfate Soils Centre, School of Biological Sciences, The University of Adelaide, Adelaide, Australia.

Published online: 22 April 2020

\section{Reference}

1. Bargrizan S, Smernik RJ, Mosley LM (2020) Constraining the carbonate system in soils via testing the internal consistency of $\mathrm{pH}, \mathrm{pCO}_{2}$ and alkalinity measurements. Geochem Trans 21:4. https://doi.org/10.1186/s1293 2-020-00069-5

\section{Publisher's Note}

Springer Nature remains neutral with regard to jurisdictional claims in published maps and institutional affiliations. 